http://dx.doi.org/10.11646/phytotaxa.125.1.5

\title{
A new species of Thismia (Thismiaceae) from Brunei Darussalam, Borneo
}

\author{
MARTIN DANČÁK ${ }^{1}$, MICHAL HRONEŠ², MICHAL SOCHOR ${ }^{2}$, LUCIE KOBRLOVÁ2, RADIM HÉDL ${ }^{3}$, \\ ZÁBOJ HRÁZSKÝ ${ }^{3,6}$, ANNA VILDOMCOVÁ ${ }^{4}$, RAHAYU SUKMARIA SUKRI ${ }^{5}$ \& FAIZAH METALI ${ }^{5}$ \\ 1 Department of Ecology \& Environmental Sciences, Faculty of Science, Palacký University, Šlechtitelu 11, CZ-78371 Olomouc, \\ Czech Republic; email: martin.dancak@upol.cz \\ 2 Department of Botany, Faculty of Science, Palacký University, Šlechtitelu 11, CZ-78371 Olomouc, Czech Republic \\ 3 Institute of Botany, Academy of Sciences of the Czech Republic, Lidická 25/27, CZ-60200 Brno, Czech Republic \\ 4 Department of Forest Botany, Dendrology and Geobiocoenology, Faculty of Forestry and Wood Technology, Mendel University, \\ Zemédělská 3, CZ-61300, Brno, Czech Republic \\ 5 Biology Programme, Faculty of Science, Universiti Brunei Darussalam, Jalan Tungku Link, BE1410, Brunei Darussalam. \\ 6 DAPHNE CZ - Institute of Applied ecology, Senovážné n. 1736, 37001 České Budějovice
}

\begin{abstract}
A new species of Thismia (Thismiaceae) from Borneo is described. Thismia hexagona was discovered in 2013 in lowland mixed dipterocarp forest in Ulu Temburong, Brunei Darussalam. The species is circumscribed, illustrated and its position within the Malesian species of the genus is characterised by insertion into the existing determination key. Its most conspicuous feature is bright yellow, sharply hexagonal flower annulus.
\end{abstract}

Kew words: tropical rain forest, mycoheterotrophy, Malesia, Burmanniaceae

\section{Introduction}

The Family Thismiaceae (Dioscoreales) is a small group of achlorophyllous mycoheterotrophic herbaceous plants, formerly treated as a tribe Thismieae in the family Burmanniaceae (Merckx et al. 2006). It contains five genera: Afrothismia Schlechter (1907: 138), Haplothismia Airy Shaw (1952: 277), Oxygyne Schlechter (1907: 140), Thismia Griffith (1844: 221) and Tiputinia Berry \& Woodward in Woodward et al. (2007: 158). Its distribution covers tropical and subtropical zones globally, with a few species extending to temperate regions (Maas-van de Kamer 1998, Woodward et al. 2007).

The genus Thismia, comprising about 50 species, is the most widespread and species-rich genus of the family Thismiaceae. It has a pantropical distribution, with two main centres of biodiversity: the Atlantic Rain Forest of South America and Southeast Asia (Jonker 1948, Mancinelli et al. 2012). Members of the genus are small herbs with reduced, scale-like leaves, actinomorphic or zygomorphic, urceolate to campanulate flowers. Perianth lobes are six, free or three inner lobes connivent at the apex forming erect mitre with three holes (Jonker 1948). After Jonker (1938), Southeast Asian species with mitre-like flowers are treated as section Sarcosiphon (Blume) Jonker (1938: 251) while species with free perianth lobes as section Thismia. The latter section is divided into two subsections: Odoardoa Schlechter (1921:34) including species with all perianth lobes that are equal in length and size, and Brunonithismia Jonker (1938: 242) including species with inner perianth lobes that are larger than outer lobes.

Members of the genus Thismia are generally poorly-known, often collected only once or a few times. They are easily overlooked in the field because of their small growth form and the ephemeral nature of their aboveground parts (Larsen \& Averyanov 2007). Many species are also likely extremely rare, with scattered distributions. As a result of these factors, it is highly possible that undescribed species can still be found in Southeast Asia (Larsen \& Averyanov 2007, Chantanaorrapint 2012). 
During our field work at Kuala Belalong Field Studies Centre (KBFSC) in the Temburong District of Brunei Darussalam in February 2013, we found a species of Thismia clearly belonging to the sect. Thismia. The section is represented by five species on the island of Borneo, but no species has been reported from Brunei Darussalam until now (Jonker 1948, Coode et al. 1996, Jarvie 1996, Tsukaya \& Okada 2005). In their general appearance and coloration, the plants resembled Thismia bifida M. Hotta (1967: 161) from Sarawak, but differed in several important morphological characters from other previously described species of the genus. We therefore report this as a first record of the family for Brunei Darussalam and describe it here as a new species for science.

\section{Description}

Thismia hexagona Dančák, Hroneš, Kobrlová \& Sochor, sp. nov., Fig. 1

Thismia hexagona differs from congeneric species in having the following combination of morphological traits: all perianth lobes equal, tapering into long filiform tentacles, stigmas bifid, yellow hexagonal annulus and four anther appendages.

Type:-BRUNEI DARUSSALAM. Temburong Distr.: Kuala Belalong, eastern ridge of Sungai Belalong, near its

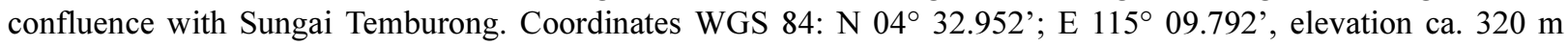
a.s.l., 13 February 2013. M. Dančák, M. Hroneš, M. Sochor \& L. Kobrlová 2013/17 (holotype BRUN [herbarium specimen, accession number 23947], isotype OL [herbarium specimen, accession number 23093]).

Terrestrial, achlorophyllous, mycoheterotrophic herb. Roots thick, hardly branched, vermiform, creeping, whitish. Stem erect, simple or poorly branched in upper part, brown, glabrous, $1.7-7.0 \mathrm{~cm}$ tall; stem branches usually unequal in length. Leaves few, appressed, scale-like, narrowly triangular, ca. $4 \mathrm{~mm}$ long, ca. $2 \mathrm{~mm}$ wide at the base, acute at the apex. Floral bracts one or two, similar in shape to the leaves, ca. $7 \mathrm{~mm}$ long, ca. $2.0-2.5 \mathrm{~mm}$ wide at the base. Flowers solitary at the top of each branch. Perianth actinomorphic with 6 tepals fused into urceolate perianth tube with free, equal apical lobes; perianth tube ca. $1.0-1.5 \mathrm{~cm}$ long, pale brownish with lower part usually white, with 12 faint brownish longitudinal streaks and brown-purple apical stripe, widest at the upper quarter, at the apex with broad bright yellow, clearly hexagonal annulus (Fig. 1B); inner surface of the perianth tube with 12 faint longitudinal ribs and densely covered with short horizontal bars; perianth lobes brown-yellowish, equally triangular, abruptly ended with long filiform appendages 7-18 $\mathrm{mm}$ long, brown-yellowish at the base, white at the top. Stamens 6 , borne on thickened margin of the perianth tube; filaments curved downwards, connective broad, connate to form a tube, with two distinct teeth-like appendages at the free apical margins and two thick cylindrical finger-shaped appendages positioned slightly above the marginal ones (Fig. 1C, D, 2D). Stigma 3-lobed, lobes shortly bifid (Fig. 1E); ovary cup-shaped usually with brown- purple stripe at the top. Fruit cup-shaped brown capsule. Seeds ellipsoid.

Habitat and ecology:- Thismia hexagona grows amongst leaf litter and on rotten logs in the lowland mixed dipterocarp forest. It prefers humid places in gullies formed by small episodic streams (Fig. 3). A total of 21 flowering individuals were found within the 1-ha permanent forest plot (Plot 1) belonging to Kuala Belalong Field Studies Centre of Universiti Brunei Darussalam (Hédl et al. 2009).

Distribution:-Species is known only from the type locality: eastern ridge of Sungai Belalong, near its confluence with Sungai Temburong. It is also the first record of the genus and family from Brunei Darussalam (cf. Coode et al. 1996, J. A. Ahmad, pers. comm.).

Conservation status:- The studied population occurs within the designated research zone of Ulu Temburong National Park, to which public access is restricted. The habitat, type locality and its surroundings are thus protected from logging and similar destructive anthropogenic activities. However, it is impossible to assess the current conservation status of this species because there is no information on its population size and dynamics. Therefore, we suggest to evaluate the species as data deficient (DD) according to the IUCN Red List Categories and Criteria (IUCN 2012). 

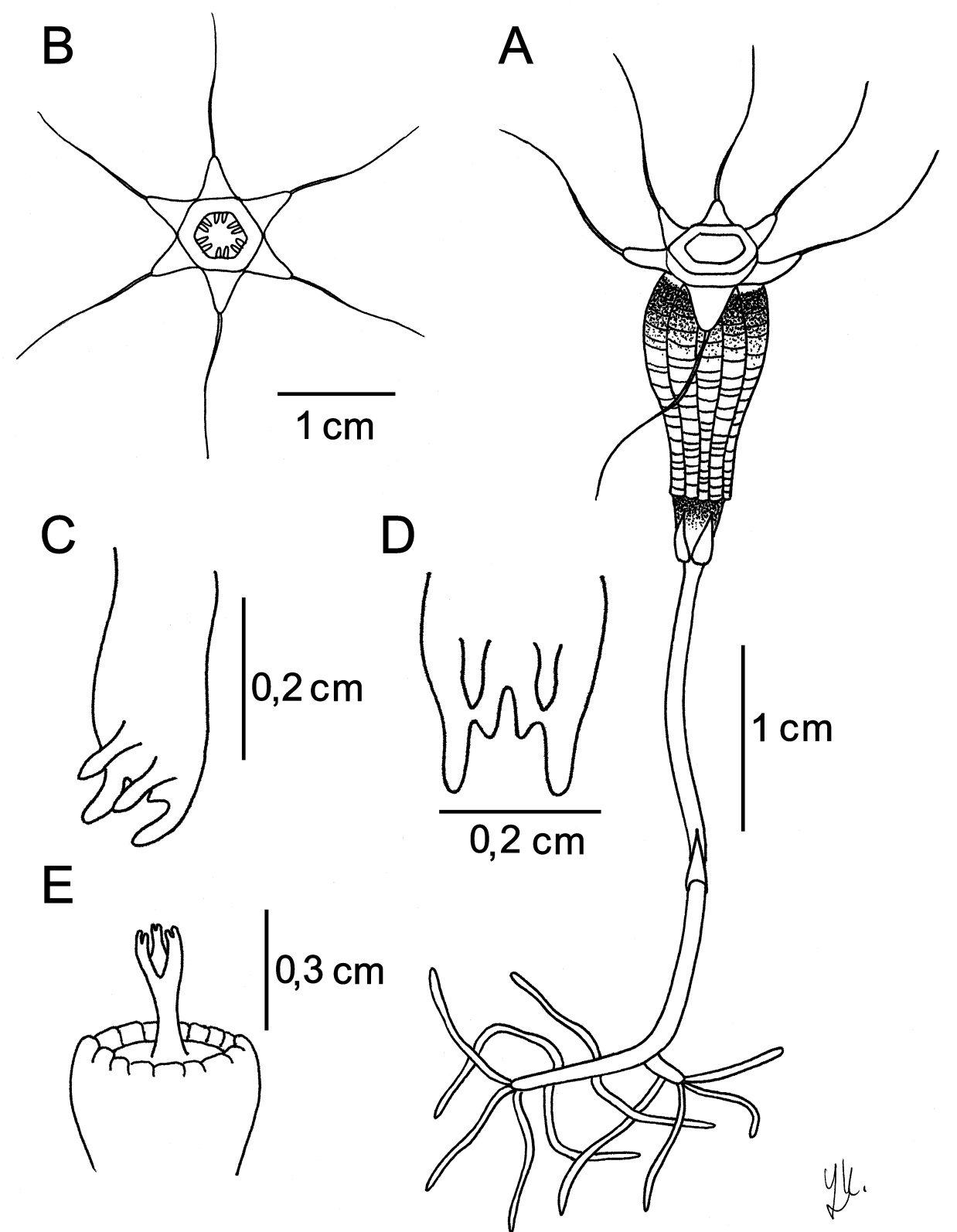

FIGURE 1. Thismia hexagona. A. Habit of the plant. B. View of perianth tube mouth with annulus and perianth lobes. C. Connective with anther appendages, side view. D. Apical margin of connective with anther appendages, front view. E. Stigma.

Etymology:-Named after the conspicuous shape of flower annulus.

Variability:-The population as a whole was uniform, with no considerable morphological variation. Most of the individuals were one-flowered, only few two-flowered and one individual with three flowers. Some variability was observed in the colour of the perianth tube. A typical individual had an almost white lower part of the perianth tube, with the upper part brownish and a more or less conspicuous brown-purple stripe at the top just beneath the annulus (Fig. 2A). We found two flowering shoots, probably originating from the same root system with a yellow stripe instead of the brown-purple one (Fig. 2B), which we suggest is a result of mutation. Few individuals had perianth tubes that were brownish throughout with almost no white basal portion. Most of the plants also had a brown-purple stripe at the top of ovary, which made an impression of two-purple-striped perianth tube. 

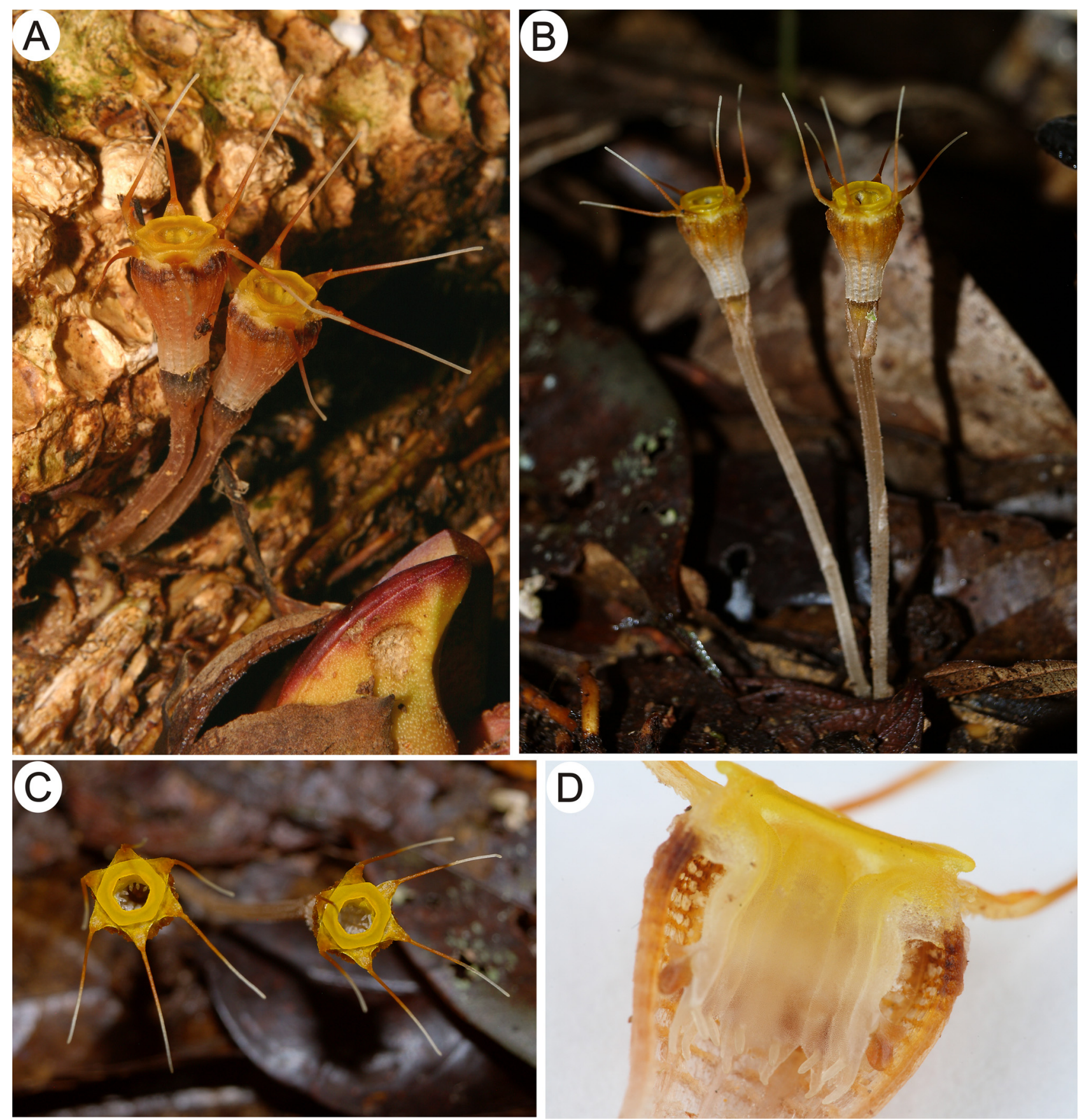

FIGURE 2. Thismia hexagona. A. Plant with typical coloration of perianth tube. B. Plant lacking brown-purple stripe at the top of perianth tube. C. Perianth tube mouth with annulus and perianth lobes. D. Longitudinal section of anther tube with anther appendages.

\section{Discussion}

It is believed by several researchers that some members of the genus Thismia could be very rare (Stone 1980, Larsen \& Averyanov 2007, Chantanaorrapint 2012). However, some of these presumed rare species may actually be neglected. The recent discoveries of Thismia alba Holttum ex Jonker (1948: 23) and T. clavigera (Beccari) F. Mueller (1891: 235) from Thailand (Chantanaorrapint \& Sridith 2007, Chantanaorrapint \& Chantanaorrapint 2009) indicate that these inconspicuous ephemeral plants tend to be overlooked or undercollected. Most Thismia species do seem to be extremely rare, usually collected only once. If this is a true observation and not an artefact of collection effort, this rarity could be caused especially by a combination of 
two mechanisms: (1) the tight bond of the plant with its host fungus and, (2) a specific mode of seed dispersion. Merckx \& Bidartondo (2008) discovered host-specific associations between members of a closely related African genus Afrothismia and arbuscular fungi from the genus Glomus Tulasne \& C. Tulasne (1845: 63). A similar pattern could also be expected in Thismia where the scarcity and limited distribution range of its fungal host may lead to the rarity of plants in this genus. With respect to seed dispersal, Stone (1980) suggested that seeds of Thismia are dispersed out of their capsules by rain-splash, thus implying that the seeds are dispersed over very short distances. These hypotheses need further studies and additional observations to be eventually accepted as plausible explanations for Thismia rarity.

From the morphological point of view, Thismia hexagona is clearly distinct from other Thismia species of the Malesian region through a combination of following traits: 1. perianth lobes all equally sized, 2. conspicuous hexagonal raised annulus, 3. bifid stigmas and 4. four anther appendages. Species that are morphologically closest to Thismia hexagona are members of sect. Thismia subsect. Odoardoa with perianth lobes triangular at the base and tapering into filiform appendages: Thismia bifida, T. lauriana Jarvie (1996: 259) and T. mullerensis Tsukaya \& Okada (1995: 129) from Borneo, Thismia aseroe Beccari (1877: 252) from Peninsular Malaysia and Thismia alba from Peninsular Malaysia and Thailand. Members of this morphologically invariable group have a round annulus, thus the hexagonal annulus of $T$. hexagona is unique within the group. Also, the number of anther appendages (four) differs from the other members of subsect. Odoardoa varying from 1 (T. alba) to 3 (T. aseroe and T. bifida). As the shape and general appearance of anthers provide useful characters for taxonomy of Thismia (Thiele \& Jordan 2002), we consider the four anther appendages in T. hexagona as an important diagnostic feature. Some species of the subsection could be superficially similar to T. hexagona due to the pattern of their coloration (Thismia alba, T. aseroe and T. bifida). However, they differ by some further morphological traits: Thismia alba and T. aseroe do not have bifid stigmas and have small perianth appendages alternating the perianth lobes while T. bifida lacks transverse bars throughout the perianth tube.

Similarly bright yellow, distinctly raised hexagonal annulus is also observed in Thismia javanica Smith (1910: 32) from the Malesian region, Thailand and Vietnam and Thismia tentaculata Larsen \& Averyanov (2007: 16) from Vietnam and China. However, these two species clearly differ from $T$. hexagona, being members of subsect. Brunonithismia, as the inner perianth lobes are larger than the outer lobes.

\section{Identification key}

The species position within Malesian species is shown by insertion into the modified key of Malesian species published by Tsukaya \& Okada (2012):

- $\quad$ Perianth lobes triangular at the base, tapering into long, filiform tentacles 7

7. Stigmas bifid.

- Stigmas not bifid.

8. Transverse bars found only in the basal part of the perianth tube. Anther appendages 3 ..................... Thismia bifida Transverse bars found throughout the perianth tube inside. Anther appendages 2 or 4

9. Annulus bright yellow, sharply hexagonal; perianth tube brownish with lower part usually white, with 12 faint brownish longitudinal streaks and dark brown-purple apical horizontal stripe; anthers with 4 finger-shaped appendages: 2 upper and 2 lower at the free apical margin of the connective

Thismia hexagona

- Annulus pale purple, round or weakly hexagonal; perianth tube white with 12 white or brownish purple longitudinal streaks; anthers with 2 appendages

10. Perianth white with brownish purple streaks; lobes with tentacles ca. $17 \mathrm{~mm}$

- Perianth white with white streaks; lobes with tentacles ca. $70 \mathrm{~mm}$.. Thismia mullerensis Thismia lauriana 


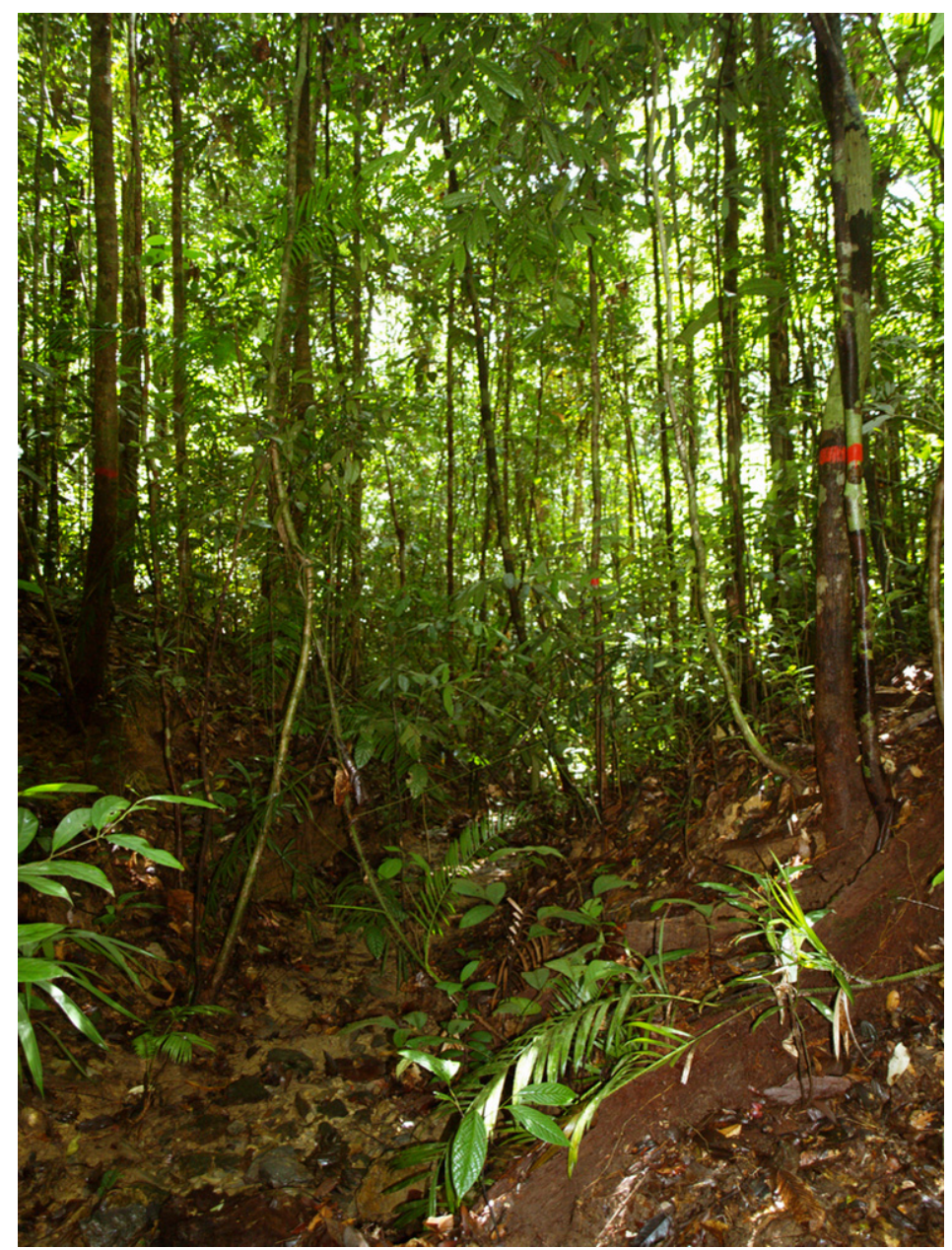

FIGURE 3. Habitat, Kuala Belalong, Brunei Darussalam.

\section{Acknowledgements}

We would like to thank staff of the Kuala Belalong Field Studies Centre for their excellent service and support during our stay at KBFSC. We also thank Universiti Brunei Darussalam for permission to conduct research at KBFSC. We are grateful to Filip Kolár who kindly provided a photocopy of relevant part of Jonker's Monograph. Filip Trnka is acknowledged for excellent photograph of anther tube. Finally, we thank to two anonymous reviewers for their comments that improved the manuscript. MD was supported by project No. CZ.1.07/2.2.00/28.0149. MH, MS and LK were supported by internal grant from Palacký University (IGA PřF 2013-003). RH and ZH were supported by the long-term research development Project No. RVO 67985939.

\section{References}

Beccari, O. (1877) Burmanniaceae. Malesia 1: 240-253.

Chantanaorrapint, S. (2012) Thismia filiformis, a new species of Thismiaceae (formerly Burmanniaceae) from Thailand. Kew Bulletin 67: 69-73. http://dx.doi.org/10.1007/s12225-012-9340-1

Chantanaorrapint, S. \& Chantanaorrapint, A. (2009) Thismia clavigera (Thismiaceae), a new record for Thailand. Thai Forest Bulletin (Botany) 37: 27-31. 
Chantanaorrapint, S. \& Sridith, K. (2007) Thismia alba (Thismiaceae), a new record for Thailand. Thai Forest Bulletin (Botany) 35: 34-37.

Coode, M.J.E., Dransfield, J., Forman, L. L., Kirkup, D. W. \& Said, I. M. (eds) (1996) A checklist of the flowering plants \& gymnosperms of Brunei Darussalam. Ministry of Industry and Primary Resources, Brunei Darussalam, 477 pp.

Griffith, W. (1844) On the root parasites referred by authors to Rhizantheae and their allies. Proceedings of the Linnean Society of London 1: 216-221.

Hédl, R., Svátek, M., Dančák, M., Rodzay, A.W., M. Salleh, A.B. \& Kamariah, A.S. (2009) A new technique for inventory of permanent plots in tropical forests: a case study from lowland dipterocarp forest in Kuala Belalong, Brunei Darussalam. Blumea 54: 124-130. http://dx.doi.org/10.3767/000651909x475482

Hotta, M. (1967) Notes on Bornean plants, II. Acta Phytotaxonomica et Geobotanica 22: 153-162.

IUCN (2012) IUCN Red List Categories and Criteria: Version 3.1. Second edition. Gland, Switzerland and Cambridge, UK, 32 pp.

Jarvie, J.K. (1996) Thismia lauriana (Burmanniaceae), a new species from central Kalimantan. Blumea 41: $257-259$.

Jonker, F.P. (1938) A monograph of the Burmanniaceae. Mededeelingen van het Botanisch Museum en Herbarium van de Rijks Universiteit te Utrecht 51: 1-279.

Jonker, F.P. (1948) Burmanniaceae. In: van Steenis, C.G.G.J. (ed.) Flora Malesiana I, 4. Noordhoff-Kolf, Leiden, pp. 1326.

Larsen, K. \& Averyanov, L.V. (2007) Thismia annamensis and T. tentaculata, two new species of the family of Thismiaceae from central Vietnam. VNU Journal of Science, Natural Sciences and Technology 23: 245-252.

Maas-van de Kamer, H.M. (1998) Burmanniaceae. In: Kubitzki, K. \& Huber, H. (eds.) Families and genera of vascular plants. Monocotyledons: Lilianae (except Orchidaceae), Springer, Berlin, pp. 154-164.

Mancinelli, W.S., Blum, C.T. \& Smidt, E.C. (2012) Thismia prataensis (Thismiaceae), a new species from the Brazilian Atlantic Rain Forest. Systematic Botany 37: 879-882. http://dx.doi.org/10.1600/036364412x656545

Merckx, V. \& Bidartondo, M.I. (2008) Breakdown and delayed cospeciation in the arbuscular mycorrhizal mutualism. Proceedings of the Royal Society B 275: 1029-1035. http://dx.doi.org/10.1098/rspb.2007.1622

Merckx, V., Schols, P., Maas-van de Kamer, H.M., Maas, P., Huysmans, S. \& Smets, E. (2006) Phylogeny and evolution of Burmanniaceae (Dioscoreales) based on nuclear and mitochondrial data. American Journal of Botany 93: 16841698 . http://dx.doi.org/10.3732/ajb.93.11.1684

Mueller, F.J.H. (1891) Notes on a new Tasmanian plant of the Order Burmanniaceae. Papers and Proceedings of the Royal Society of Tasmania 1890: 232-235.

Schlechter, F.R.R. (1907) Burmanniaceae africanae. Botanische Jahrbücher für Systematik, Pflanzengeschichte und Pflanzengeographie 38: 137-143.

Schlechter, F.R.R (1921) Die Thismieae. Notizblatt des Königlichen botanischen Gartens und Museums zu Berlin 8: 3145.

Smith, J.J. (1910) Beiträge zur Kenntnis der Saprophyten Javas. I. Zur Systematik von Thismia javanica J. J. S. Annales du Jardin botanique de Buitenzorg 23: 32-35.

Stone, B.C. (1980) Rediscovery of Thismia clavigera (Becc.) F. v. M. (Burmanniaceae). Blumea 26: 419-425.

Thiele, K.R. \& Jordan, P. (2002) Thismia clavarioides (Thismiaceae), a new species of Fairy Lantern from New South Wales. Telopea 9: 765-771.

Tsukaya, H. \& Okada, H. (2005) Thismia mullerensis (Burmanniaceae), a new species from Muller Range, Central Kalimantan. Acta Phytotaxonomica et Geobotanica 56: 129-133.

Tsukaya, H. \& Okada, H. (2012) A new species of Thismia (Thismiaceae) from West Kalimantan, Borneo. Systematic Botany 37: 53-57. http://dx.doi.org/10.1600/036364412x616639

Tulasne, L.R. \& Tulasne, C. (1845) Fungi nonulli hypogaei, novi v. minus cogniti. Giornale Botanico Italiano 1: $55-63$.

Woodward, C.L., Berry, P.E., Maas-van de Kamer, H.M. \& Swing, K. (2007) Tiputinia foetida, a new mycoheterotrophic genus of Thismiaceae from Amazonian Ecuador, and a likely case of deceit pollination. Taxon 56: 157-162. 